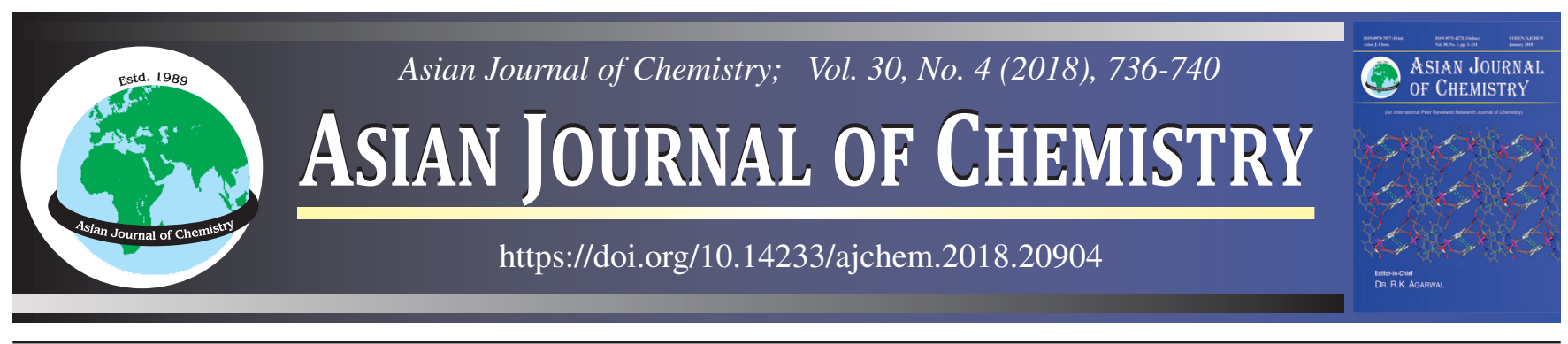

\title{
Alginate/Chitosan Nanoparticles for Improved Oral Delivery of Rifampicin: Optimization, Characterization and in vitro Evaluation
}

\author{
DeEPa Thomas ${ }^{1,2}$, M.S. Latha ${ }^{2,3, *}$ and K. KuRIEn Thomas ${ }^{1}$
}

${ }^{1}$ Research and Post Graduate Department of Chemistry, Bishop Moore College, Mavelikara-690 110, India

${ }^{2}$ Department of Chemistry, Sree Narayana College, Kollam-691 001, India

${ }^{3}$ Department of Chemistry, Sree Narayana College, Chengannur-689 508, India

*Corresponding author: E-mail: lathams2014@gmail.com

Received: 3 July 2017;

Accepted: 29 September 2017;

Published online: 28 February 2018;

AJC-18774

\begin{abstract}
Alginate/chitosan nanoparticles were synthesized by ionotropic method using natural honey as the stabilizing agent. The nanoparticles were characterized and the potential of these nanoparticles for the controlled oral delivery of antitubercular drug rifampicin was evaluated in terms of entrapment efficiency, swelling behaviour and in vitro release of the drug. Carboxyl content and in vitro cytotoxicity of the nanoparticles were also evaluated. The swelling and in vitro drug release indicates that the system undergoes $\mathrm{pH}$-dependent swelling and release of drug. Drug release was very low in acidic $\mathrm{pH}$ and a maximum of only $20 \%$ of the drug was released in $5 \mathrm{~h}$. A sustained release of drug was observed at $\mathrm{pH} 7.4$ and complete release was obtained in $8 \mathrm{~h}$. Kinetics of the drug release was analyzed by fitting the experimental data into Korsmeyer-Peppas equation and show that the mechanism involved in the release was non-Fickian, controlled by a combined mechanism of diffusion and polymer relaxation. This study shows that the obtained nanoparticles can be a potential carrier for the $\mathrm{pH}$ controlled oral delivery of rifampicin.
\end{abstract}

| Keywords: Rifampicin, Sodium alginate, Chitosan, Nanoparticle, Honey, Controlled release.

ᄂ ------------------------------$\lrcorner$

\section{INTRODUCTION}

Tuberculosis (TB) caused by Mycobacterium tuberculosis, is a chronic communicable and persistent bacterial infection. The current tuberculosis therapy involves the daily administration of combination of antituberculosis drugs for a period of more than 6 months [1]. But due to limited solubility, rapid and premature degradation and low cellular uptake of these drugs, concentration of the drug reached to target site is less than the therapeutic level. The prolonged drug administration often causes several side effects such as nausea, nephrotoxicity, hepatotoxicity, fever and vomiting. This may results in the patients non-compliance and chance for treatment failure [2]. Treatments based on controlled release drug delivery systems using polymeric micro and nanoparticles is one of the best solution for the problems related to the existing tuberculosis therapy. There are various efforts have been made to develop micro and nano polymer [3]. But some of them include complex preparation steps, inconvenient routes of administration and toxicity problems [4]. Oral controlled delivery of rifampicin (RIF) using nano formulation can be improved the efficacy of tuberculosis therapy and the patient comfort. The key factors involved in the selection of carrier in drug delivery application are its size, shape, drug loading and encapsulation efficiency [5]. Nano particulate drug delivery formulations have the potential to improve these factors and also capable to increase the drug solubility. Alginate a water soluble linear polysaccharide, composed of $\beta$-D-mannuronic acid and $\alpha$-Lguluronic acid $(\mathrm{G})$ is extracted from brown seaweed and is widely used for the bio encapsulation of drugs without the risk of mucosal damage. But, low durability, high-diffusion rates resulting from the high porosity and limited mechanical stability were the major drawbacks of alginate based drug delivery system [6]. Chitosan, a natural cationic polymer, has the capacity to interact with anionic bio macromolecules and enhance their loading as holds them tightly. Ribeiro and co-workers could successfully retarded the release of haemoglobin from alginate micro particles by chitosan coating [7]. The studies made by Wittaya-areekul et al. [8] and Takka \& Gürel [9] revealed that the incorporation of chitosan into alginate micro particles enhances its bioadhessive nature. Oral delivery with alginate nanoparticles coated with chitosan is expected to offer advantages of controlled drug delivery, high drug payload and improved stability. It also ensure protection for encapsulated drugs from acidic environment of gastrointestinal tract and enzyme degradation. The small size of nanoparticles increases 
the specific surface area and allowing increased contact area with the epithelial surface and results in greater uptake of drugs. However, the formulation and application of alginate-chitosan nanoparticles, have not gained much attention as the alginatechitosan microparticles. Honey has antibacterial and antifungal properties and has been used in Ayurveda medicine of India, as a vehicle for faster absorption of various drugs such as herbal extracts. It also supports the treatment of several specific ailments, particularly those related to respiratory irritations and infections, mouth sores and eye cataracts $[10,11]$. The objective of the present work was to develop alginate-chitosan (ALG-CH nanoparticles) using natural honey as stabilizer, an ideal drug delivery system that is potentially expected to provide $\mathrm{pH}$ dependent drug release, with increased bioavailability of the drug, prolonged circulation time and reduced side effects. The nanoparticles developed were loaded with rifampicin and characterized for the application towards its utilization as a carrier for rifampicin. In vitro release kinetics from these nanoparticles was studied. From the present study, it is found that ALG-CH nanoparticles are excellent carrier system for the controlled delivery of rifampicin.

\section{EXPERIMENTAL}

Low viscosity sodium alginate powder (Sigma-Aldrich, London), chitosan (Sigma-Aldrich, London), rifampicin (Himedia Laboratories, Nasik), calcium chloride dihydrate (Merck, Germany) were of analytical grade and used as such without any further purification. Natural honey used in this study was procured from Kerala Agriculture University.

Preparation of alginate nanoparticle: Alginate-chitosan nanoparticles were prepared by ionotropic gelation technique with slight modification. Sodium alginate was dissolved in aqueous honey (added as surfactant and stabilizer) solution (1 $\%, \mathrm{w} / \mathrm{v})$. Chitosan was dissolved in aqueous acetic acid $(0.25 \%$, $\mathrm{w} / \mathrm{v}$ ) and is added to sodium alginate solution. It was followed by the addition of rifampicin $(0.5 \%, \mathrm{w} / \mathrm{v})$. Aqueous calcium chloride solution $(1 \%, \mathrm{w} / \mathrm{v})$ was added drop-wise into this solution with continuous stirring using a magnetic stirrer. $\mathrm{pH}$ of the entire solution was maintained at 5.5. This homogenized mixture was sonicated for $5 \mathrm{~min}$. Nanoparticles were collected by centrifugation at $3500 \mathrm{rpm}$ for $5 \mathrm{~min}$, washed and dried under vacuum [12]. The ratio of alginate to chitosan was optimized on the basis of their effect on drug entrapment efficiency.

Material characterization methods: Fourier transform infrared (FTIR) spectra of alginate, chitosan, rifampicin, ALG$\mathrm{CH}$ nanoparticles and rifampicin loaded ALG-CH nanoparticles were recorded between 4000 and $400 \mathrm{~cm}^{-1}$ wavelength range using Shimadzu FTIR model 1801. Surface morphology of the ALG-CH nanoparticles was probed using a JEOL JSM6390LA analytical scanning electron microscope. Transmission electron microscopy (TEM) was performed using JEOL model $1200 \mathrm{EX}$ instrument operated at an accelerating voltage at 80 $\mathrm{kV}$. XRD patterns of the samples were recorded by using Brucker D8 Advance diffractometer with monochromatic $\mathrm{Cu}-\mathrm{K} \alpha_{1}$ radiation $(\lambda=1.5418 \AA)$.

Swelling behaviour: The swelling behaviour of nanoparticles were determined by tea-bag method [13]. A known amount of dried sample $\left(\mathrm{W}_{\mathrm{d}}\right)$ was taken in a previously weighed tea bag (of suitable mesh size) and allowed to swell in solution of $\mathrm{pH} 1.2$ and 7.4 respectively for a specific period. The swollen samples were taken out and weighed immediately after removing the excess liquid from the surface using filter paper $\left(\mathrm{W}_{\mathrm{s}}\right)$. The percentage of swelling was calculated using the equation. Data were given as mean \pm standard deviation (SD) based on 3 independent measurements.

$$
\mathrm{SD}=\left(\frac{\mathrm{W}_{\mathrm{s}}-\mathrm{W}_{\mathrm{d}}}{\mathrm{W}_{\mathrm{d}}}\right) \times 100
$$

Estimation of carboxyl group: Carboxyl groups present in ALG-CH nanoparticles before and after cross linking was determined by the Boehm titration method [14]. About $0.1 \mathrm{~g}$ sample was shaken with sodium bicarbonate $(30 \mathrm{~mL}, 0.1 \mathrm{M})$ for $20 \mathrm{~h}$ at room temperature and filtered. Excess $\mathrm{HCl}(0.05 \mathrm{M})$ was added to $10 \mathrm{~mL}$ of filtrate, boiled off $\mathrm{CO}_{2}$, cool the solution and back titrated with $\mathrm{NaOH}(0.05 \mathrm{M})$. The amount of carboxyl group was calculated using the equation.

$$
\mathrm{COOH}\left(\frac{\mathrm{meq}}{\mathrm{g}}\right)=\frac{\left(\mathrm{C}_{\mathrm{NaOH}} \times \mathrm{V}_{\mathrm{NaOH}}-\mathrm{C}_{\mathrm{HCl}} \times \mathrm{V}_{\mathrm{HCl}}\right)}{\mathrm{W}}
$$

Cytotoxicity evaluation: The in vitro toxicity of ALG$\mathrm{CH}$ nanoparticles were measured using L929 fibroblast by MTT assay. The cells were cultured with DMEM containing $10 \%$ FBS and the cultured cell lines were kept at $37^{\circ} \mathrm{C}$ in a humidified $5 \% \mathrm{CO}_{2}$ incubator for $24 \mathrm{~h}$. The medium was then replaced with test solution of different concentration $(100 \mu \mathrm{g}$, $50 \mu \mathrm{g}, 25 \mu \mathrm{g}, 12.5 \mu \mathrm{g}, 6.25 \mu \mathrm{g} / \mathrm{mL}$ ) and incubated at $37^{\circ} \mathrm{C}$ in a humidified $5 \% \mathrm{CO}_{2}$ incubator for specified time. Later 30 $\mu \mathrm{L}$ of MTT $(5 \mathrm{mg} / \mathrm{mL})$ was added to the wells and incubated at $37{ }^{\circ} \mathrm{C}$ in a humidified $5 \% \mathrm{CO}_{2}$ incubator for $4 \mathrm{~h}$. After the incubation period, the supernatant was removed and $100 \mu \mathrm{L}$ DMSO was added to solubilize the formazan crystals. The absorbance values were measured by using micro plate reader at a wavelength of $570 \mathrm{~nm}$ to determine the optical density (OD). Optical density of control was obtained from the cells by repeating the above experiment without any sample. Cell viability (\%) was calculated using eqn. 3 .

$$
\text { Cell viability }(\%)=\left(\frac{\text { OD of sample }}{\text { OD of control }}\right) \times 100
$$

Determination of entrapment efficiency of nanoparticles: The concentration of non-encapsulated rifampicin was determined by the absorbance at $475 \mathrm{~nm}$, using a UV-visible spectrophotometer (Perkin Elmer Lambda Bio 40). The drug entrapment efficiency ( $\% \mathrm{EE}$ ) was calculated by eqn. 4 as follows:

$$
\mathrm{EE}(\%)=\left(\frac{\text { Weight of RIF in ALG-CH NPs }}{\text { Weight of RIF used for loading }}\right) \times 100
$$

Data were given as mean \pm standard deviation (SD) based on 3 independent measurements.

In vitro drug release: In vitro drug release studies were carried out in simulated gastric fluid (SGF, pH 1.2) and simulated intestinal fluid (SIF, $\mathrm{pH}$ 7.4) prepared according to the United States Pharmacopoeia at $37{ }^{\circ} \mathrm{C}$ under shaking conditions [15]. Aliquots were drawn at specific time intervals and replaced with equal volume of buffer. The rifampicin-loaded nanoparticles were separated from the aqueous suspension by 
ultra-centrifugation at $10,000 \mathrm{rpm}$ for $10 \mathrm{~min}\left(\mathrm{SORALL}^{\circledR}\right.$ Bioguge Stratos Ultracentrifuge). Rifampicin's concentration was determined by the absorbance at $475 \mathrm{~nm}$ in a UV-visible spectrophotometer (Perkin Elmer Lambda Bio 40). Data were given as mean \pm standard deviation (SD) based on 3 independent measurements.

Drug release kinetics: To find out the drug release mechanism, the drug release data was analyzed using KorsmeyerPeppas equation eqn. 5.

$$
\frac{\mathrm{Q}_{\mathrm{t}}}{\mathrm{Q}_{\propto}}=\mathrm{kt}^{\mathrm{n}}
$$

$\mathrm{Q}_{\mathrm{V}} / \mathrm{Q}_{\propto}$ is fraction of drug released at time $\mathrm{t}, \mathrm{K}$ is the rate constant and $\mathrm{n}$ is the release exponent. In this model, the value of $\mathrm{n}$ identifies the release mechanism of drug. The values of these parameters vary with the geometric form of the system, that is, thin film, cylindrical or spherical. For a spherical system $\leq$ 0.43 indicates Fickian release and $\mathrm{n}=0.85$ indicates a purely relaxation-controlled delivery which is referred to as Case II transport. Intermediate values $0.43<\mathrm{n}<0.85$ indicate an anomalous behaviour (non-Fickian kinetics) corresponding to coupled diffusion/polymer relaxation been observed [16-18].

\section{RESULTS AND DISCUSSION}

Preparation and characterization of rifampicin loaded alginate nanoparticle: Hybrid nanostructures of natural polymers are of broad technological interest in drug delivery applications as they are nontoxic and biocompatible in nature. Hybrid structures offer the possibility of tuning release characteristics and pharmacological performance by varying the concentration and functional properties of the components. Here a green method was adopted for the preparation of ALG-CH nanoparticles using water as solvent and honey as the stabilizing agent. Formation of nanoparticle was found to be dependent on the concentration and $\mathrm{pH}$ of the solution. Critical condition for nano formation was found to be at 4:1 alginate-chitosan ratio and a $\mathrm{pH}$ of 5.5. The results of optimized parameters are summarized in Table-1.

TABLE-1

ENTRAPMENT EFFICIENCY OF VARIOUS FORMULATIONS OF ALG-CH NANOPARTICLE

\begin{tabular}{cc}
\hline ALG:CH (weight ratio) & Entrapment efficiency $(\%)$ \\
\hline $1: 1$ & $42.31 \pm 1.9$ \\
$2: 1$ & $45.76 \pm 3.5$ \\
$3: 1$ & $50.87 \pm 2.8$ \\
$4: 1$ & $55.62 \pm 2.6$ \\
$5: 1$ & $48.56 \pm 3.1$ \\
\hline
\end{tabular}

On the addition of calcium chloride, the $\mathrm{Ca}^{2+}$ induced interchain association via carboxyl group of $\mathrm{G}$ units, leading to the formation of junction zones $[19,20]$. Unlike other organic surfactants, here natural honey was used as the stabilizing agent [21]. FTIR was used to characterize the potential interactions in the nanoparticles. The FTIR spectrum of ALG, $\mathrm{CH}$, rifampicin, neat ALG-CH nanoparticle and rifampicin loaded ALG$\mathrm{CH}$ nanoparticle are given in Fig. 1. The carboxylate groups of alginate associated with the amino groups of chitosan through electrostatic interactions to form the polyelectrolyte

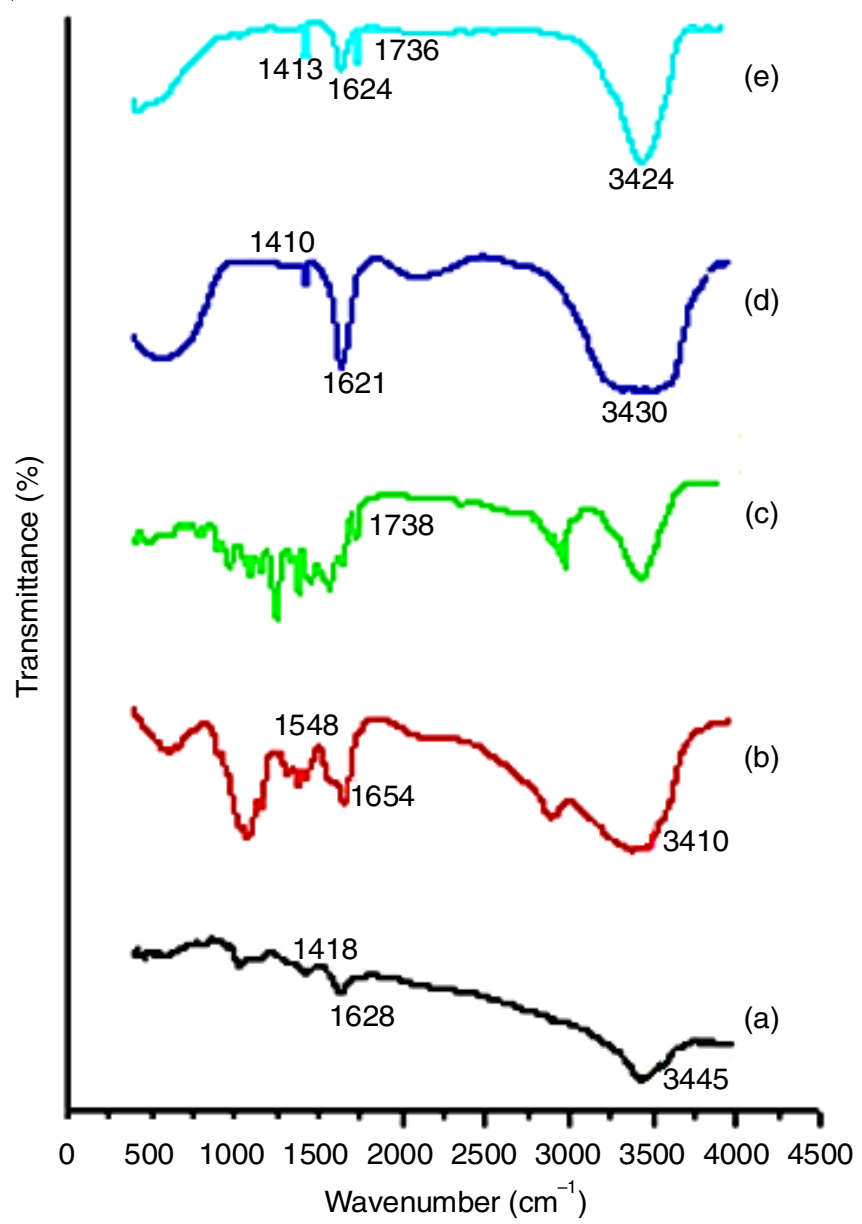

Fig. 1. FTIR of (a) alginate (b) chitosan (c) rifampicin (d) ALG-CH (e) rifampicin loaded ALG-CH nanoparticle

complex. This is confirmed by the notable shift in the position of the amide I vibration (1654 to $1621 \mathrm{~cm}^{-1}$ ) of chitosan. The characteristic peak of rifampicin at $1741 \mathrm{~cm}^{-1}$ corresponds to furanone ring structure. This band can also be seen in the rifampicin loaded ALG-CH nanoparticle, indicating that the rifampicin molecule was incorporated into the polymeric network of the nanoparticle and there is no interaction between the drug and polymeric network [22,23].

The shape and surface morphology of the system was characterized by SEM and TEM and is given in Fig. 2. The SEM images show the presence of well-defined spherical nanoparticles. It was confirmed from TEM and indicates the presence of nanoparticles of size less than $100 \mathrm{~nm}$. The presence of honey help to reduce the particle size. The XRD patterns of the rifampicin and rifampicin loaded ALG-CH nanoparticles is shown in Fig. 3. The powder X-ray diffraction of rifampicin revealed its crystalline character showing major peaks at $2 \theta=10.7$, 15.4, 16.6, 17.6, 19.5, 21, 22.7, 25, 27 and 29. In rifampicin loaded ALG-CH nanoparticle, the disappearance of the crystalline peaks of the drug is indicative of its actual amorphization during the nanoparticle preparation.

Swelling behaviour: The swelling behaviour of ALG$\mathrm{CH}$ nanoparticles were determined in simulated gastric fluid (SGF, pH 1.2, Fig. 4 a) and intestinal fluid (SIF, pH 7.4, Fig. 4b) at room temperature. Swelling behaviour of nanoparticle has a profound effect on the mechanism and kinetics of drug release. 

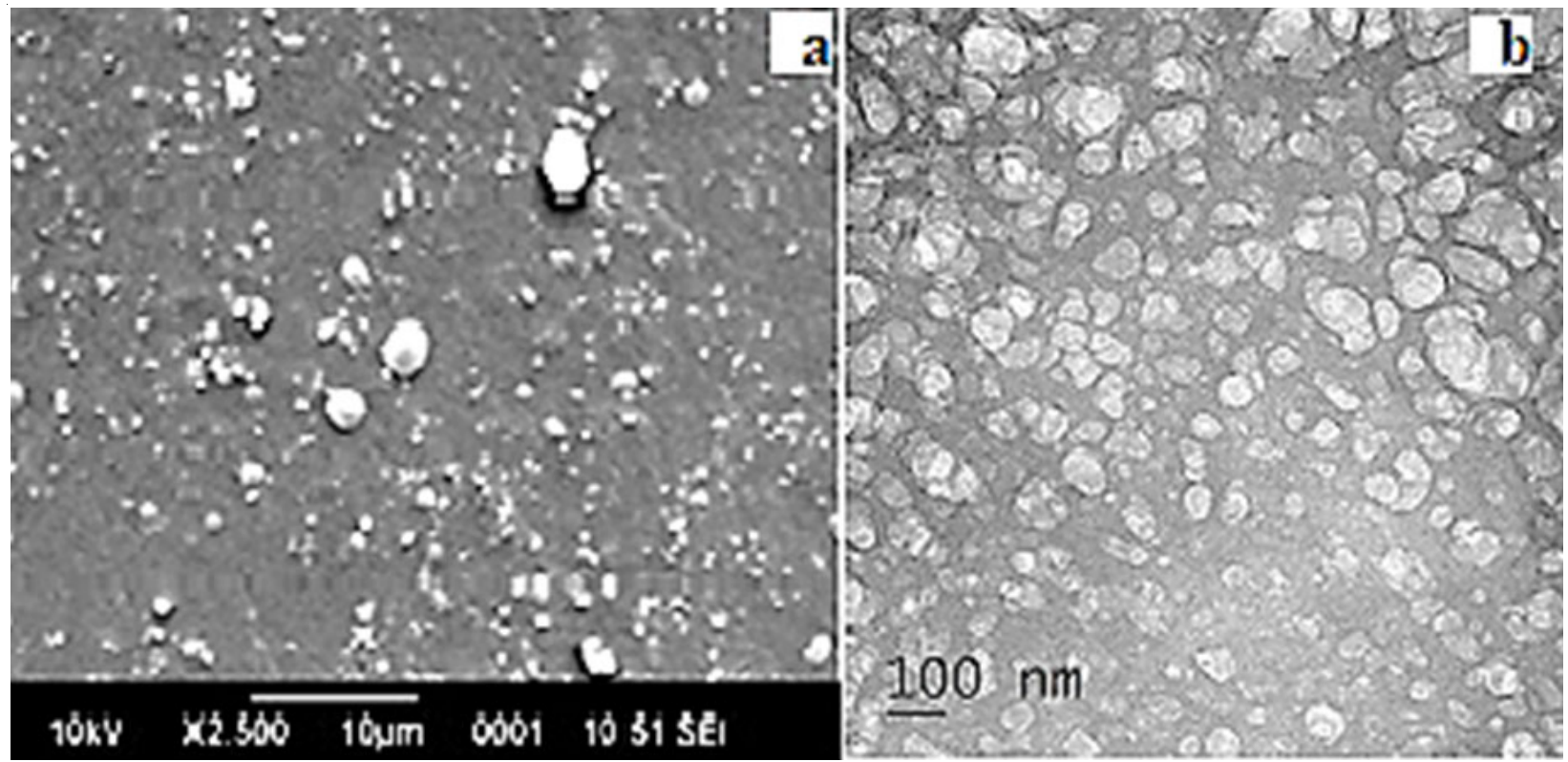

Fig. 2. (a) SEM and (b) TEM images of ALG-CH nanoparticle

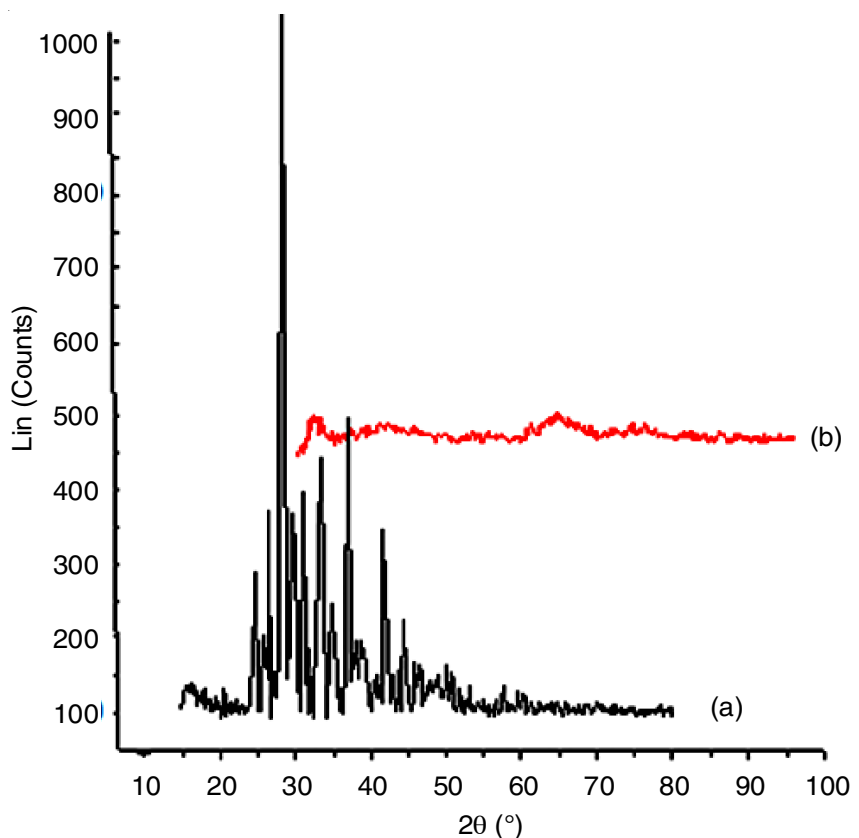

Fig. 3. XRD pattern of (a) rifampicin and (b) rifampicin loaded ALG-CH nanoparticle

At low $\mathrm{pH}$ ( $\mathrm{pH} 1.2)$ the swelling was very low. In acidic medium, the carboxylate groups of alginate are protonated and are converted to insoluble alginic acid. The electrostatic repulsion among carboxylate groups reduces swelling. The disappearance of electrostatic repulsions favours the shrinkage of nanoparticle. The percentage swelling of nanoparticles were higher at $\mathrm{pH}$ 7.4. In ALG-CH nanoparticles there exists some electrostatic interactions between the $-\mathrm{NH}_{3}{ }^{+}$groups of chitosan chains and the $-\mathrm{COO}^{-}$groups of alginate. It provides a strong and compact layer and improves the stability of ALG-CH nanoparticles and ultimately prolonging the time for degradation and collapse. These observations showed that ALG-CH nanoparticles undergoes $\mathrm{pH}$-dependent swelling, in which the carboxylate and amino groups respond to stimuli from the environment in which they are inserted. The amount of the free carboxyl group
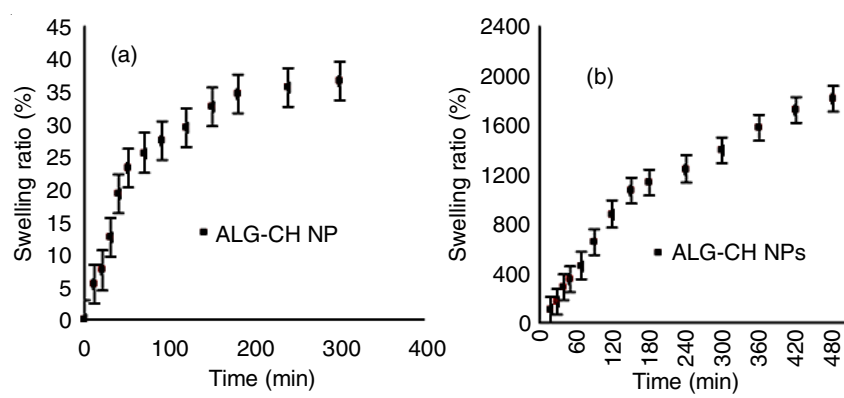

Fig. 4. Swelling behaviour of ALG-CH nanoparticles in (a) $\mathrm{pH} 1.2$ (b) $\mathrm{pH} 7.4$

in nanoparticles before and after cross linking were found to be $3.15 \mathrm{meq} \mathrm{g}^{-1}$ and $2.20 \mathrm{meq} \mathrm{g}^{-1}$ respectively.

Cytotoxicity: The cytotoxicity of ALG-CH nanoparticle was evaluated by MTT assay on L929 cell lines at different concentrations and the results shown in Fig. 5. From this graphical representation, it was found that the obtained nanoparticle has no toxicity and suited for drug delivery applications.

In vitro drug release: The in vitro drug release studies were performed in the fluids simulating the conditions of

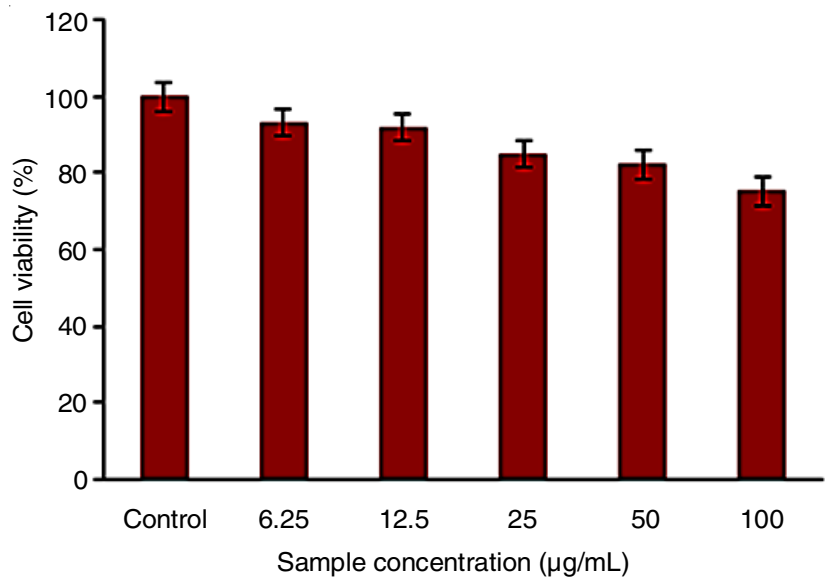

Fig. 5. In vitro cell viability of L929 cells treated with ALG-CH nanoparticle 
gastrointestinal (GI) tract for $0-5 \mathrm{~h}$ in SGF (pH 1.2) and 0-8 h in SIF (pH 7.4) Fig. 6. The amount of rifampicin released in SGF at pH 1.2 is very low. Only $15-20 \%$ of rifampicin is released from ALG-CH nanoparticle. At this $\mathrm{pH}$, these nanoparticles were not eroded, the negative-COO group of calcium alginate protonated and acted as a diffusion barrier for the release of the drug. In vitro drug release was higher in the SIF compared to the SGF. At $\mathrm{pH} 7.4$ a rapid increase in the release rate was observed up to $100 \%$ in $8 \mathrm{~h}$. This can be attributed to the introduction of chitosan that may have restricted the motion of the alginate polymer chains and thereby improving the entrapment and controlled release behaviours. Chitosan also acts as a reinforcing polymer to retard the erosion of alginate nanoparticles, which explains the slow, but sustained in vitro drug release.

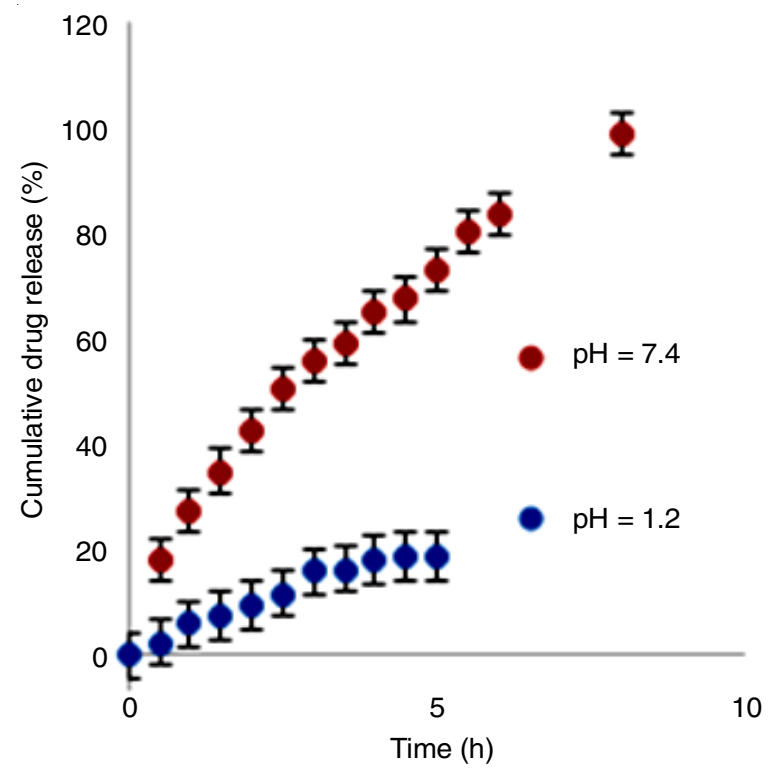

Fig. 6. Rifampicin cumulative release from ALG-CH nanoparticle in $\mathrm{pH}$ 1.2 and 7.4

Drug release kinetics: The drug release kinetics of rifampicin from nanoparticles was analyzed by fitting the release data with Korsmeyer-Peppas model. The value of the release exponent $\mathrm{n}$ was 0.77 for ALG-CH nanoparticles which indicate an anomalous, non-Fickian kinetics corresponding to coupled diffusion/polymer relaxation mechanism.

\section{Conclusion}

Alginate-chitosan nanoparticles containing rifampicin were obtained successfully by simple ionotropic gelation method using natural honey as stabilising agent. The morphological analysis carried out by SEM and TEM revealed that the polymers used in the formulations conferred particular surface characteristics to the polymeric nanoparticles. The drug release and swelling were $\mathrm{pH}$-dependent. The drug was well protected in the acidic environment of gastric fluid and released completely in intestinal fluid. In vitro cytotoxicity studies indicate that the nanoparticles are biocompatible. The values obtained for the release parameters indicate an anomalous transport mechanism. This study demonstrates that the nanoparticles developed provide a good system for the controlled-release of rifampicin.

\section{ACKNOWLEDGEMENTS}

This work was supported by the University Grants Commission, New Delhi, India (FIP/12 $2^{\text {th }}$ plan/KLKE002TF05).

\section{REFERENCES}

1. E. Nuermberger and J. Grosset, Eur. J. Clin. Microbiol. Infect. Dis., 23, 243 (2004); https://doi.org/10.1007/s10096-004-1109-5.

2. R. Parmar, R. Misra and S. Mohanty, Colloids Surf. B: Biointerfaces, 129, 198 (2015); https://doi.org/10.1016/j.colsurfb.2015.03.051.

3. D. He, P. Deng, L. Yang, Q. Tan, J. Liu, M. Yang and J. Zhang, Colloids Surf. B: Biointerfaces, 103, 580 (2013);

https://doi.org/10.1016/j.colsurfb.2012.10.062.

4. P. O'Hara and A.J. Hickey, Pharm. Res., 17, 955 (2000); https://doi.org/10.1023/A:1007527204887.

5. W. Liu, W.D. Wu, C. Selomulya and X.D. Chen, Powder Technol., 236, 188 (2013);

https://doi.org/10.1016/j.powtec.2012.02.012.

6. K. Moebus, J. Siepmann and R. Bodmeier, Eur. J. Pharm. Biopharm., 72, 42 (2009); https://doi.org/10.1016/j.ejpb.2008.12.004.

7. A.J. Ribeiro, C. Silva, D. Ferreira and F. Veiga, Eur. J. Pharm. Sci., 25, 31 (2005);

https://doi.org/10.1016/j.ejps.2005.01.016.

8. S. Wittaya-areekul, J. Kruenate and C. Prahsarn, Int. J. Pharm., 312, 113 (2006);

https://doi.org/10.1016/j.ijpharm.2006.01.003.

9. S. Takka and A. Gürel, AAPS PharmSciTech, 11, 460 (2010); https://doi.org/10.1208/s12249-010-9406-z.

10. S.K. Motwani, S. Chopra, S. Talegaonkar, K. Kohli, F.J. Ahmad and R.K. Khar, Eur. J. Pharm. Biopharm., 68, 513 (2008); https://doi.org/10.1016/j.ejpb.2007.09.009.

11. R. Singh and J.W. Lillard Jr., Exp. Mol. Pathol., 86, 215 (2009); https://doi.org/10.1016/j.yexmp.2008.12.004.

12. P. Geetha, M.S. Latha, S.S. Pillai and M. Koshy, Ecotoxicol. Environ. Saf., 122, 17 (2015); https://doi.org/10.1016/j.ecoenv.2015.06.032.

13. E. Al, G. Güçlü, T.B. Iyim, S. Emik and S. Özgümüs, J. Appl. Polym. Sci., 109, 16 (2008);

https://doi.org/10.1002/app.27968.

14. T.S. Anirudhan, Binusreejayan and J.R. Deepa, J. Appl. Polym. Sci., 133, 434 (2016); https://doi.org/10.1002/app.43479.

15. M.D. Rockville, The United States Pharmacopeial Convention, US Pharmacopeia, XXVI/NF, 2528 (2003)

16. R.W. Korsmeyer, R. Gurny, E. Doelker, P. Buri and N.A. Peppas, Int. J. Pharm., 15, 25 (1983); https://doi.org/10.1016/0378-5173(83)90064-9.

17. P.L. Ritger and N.A. Peppas, J. Control. Rel., 5, 23 (1987); https://doi.org/10.1016/0168-3659(87)90034-4.

18. P.L. Ritger and N.A. Peppas, J. Control. Rel., 5, 37 (1987); https://doi.org/10.1016/0168-3659(87)90035-6.

19. P. Sikorski, G.Skjåk-Bræk and B.T. Stokke, Biomacromolecules, 8, 2098 (2007); https://doi.org/10.1021/bm0701503.

20. E.V.R. Campos, N.F.S. de Melo, E. de Paula, A.H. Rosa and L.F. Fraceto, J. Colloid Sci. Biotechnol., 2, 106 (2013); https://doi.org/10.1166/jcsb.2013.1040.

21. J.S. Yang, H.B. Ren and Y.J. Xie, Biomacromolecules, 12, 2982 (2011); https://doi.org/10.1021/bm200571k.

22. C. Sartori, D.S. Finch, B. Ralph and K. Gilding, Polymer, 38, 43 (1997); https://doi.org/10.1016/S0032-3861(96)00458-2.

23. L. Lacerda, A.L. Parize, V. Fávere, M.C.M. Laranjeira and H.K. Stulzer, Mater. Sci. Eng., 39, 161 (2014); https://doi.org/10.1016/j.msec.2014.01.054. 